\title{
VIBRATION COMPENSATION USING DUMMY LOAD-CELL IN DYNAMIC MASS MEASUREMENT
}

\author{
Y. Yamakawa ${ }^{1}$, A. Tsuzura ${ }^{2}$, T. Yamazaki ${ }^{3}$ \\ ${ }^{1}$ The University of Tokyo, Tokyo, Japan, y-ymkw@iis.u-tokyo.ac.jp \\ 2 Tokyo Denki University, Saitama, Japan \\ ${ }^{3}$ Tokyo Denki University, Saitama, Japan, yamazaki@mail.dendai.ac.jp
}

\begin{abstract}
:
Checkweighers, that can measure the mass of a target object continuously while conveying the object on a belt conveyor, are affected by environmental vibration. As a result, accuracy of the mass measurement gets worse. To solve this problem, we have proposed a method that can eliminate the effect of the environmental vibration. This paper enhances the proposed method and improves the performance of the proposed method.
\end{abstract}

Keywords: checkweigher; mass measurement; load cell; vibration compensation; dummy load cell

\section{INTRODUCTION}

Checkweighers are devices that can measure the mass of a target object continuously while conveying the object on a belt conveyor. The checkweighers has operating an active role in various fields such as food, medicine, and industrial products.

Recently, a dynamic mass measurement rather than a conventional static mass measurement has been focused on. Some studies related to the dynamic mass measurement have been done actively. To achieve the dynamic mass measurement with high accuracy contributes to the continuous mass measurement at high speed. However, there exists a problem that a disturbance such as a floor vibration affects an accuracy of the dynamic mass measurement strongly. In fact, although load cell scales are often used to measure the mass of the object in the checkweigher, the measurement accuracy is susceptible to environmental vibration due to the structure of the load cells.

In order to solve the problems described above, some researches have been conducted using a load cell up to the present date. Kamimura et al. showed that the accuracy of mass measurement has improved by designing the FIR filter that removes the environmental vibration for the load cell [1]. Umemoto et al. proposed a notch filter that can remove only signals of specific frequency components, and the transfer speed is improved by applying it to the checkweigher [2]. Sun et al. suggested a method to remove environmental vibration using signal processing by newly installing a load cell for vibration detection separately from the measurement load cell. In this method, the natural frequencies of the two load cells do not match (there exists a difference in dynamic characteristics), which may adversely affect the measurement accuracy. Hence, by applying the principle of relative compensation, it has been shown to improve the accuracy of mass measurement [3]. In addition, it takes $40 \mathrm{~ms}$ to identify on-line in this method, and high-speed mass measurement is difficult. Hence, the shortening of identification time was considered by the compensation of the difference in dynamic characteristics using a polynomial approximation model [4]. We have proposed EMFC (ElectroMagnetic Force Compensation) system for measuring the mass at high speed. Moreover, we constructed the mathematical model of the EMFC system, which can duplicate the dynamic behaviour with high accuracy [5]. Using the mathematical model, we also proposed the reduction method for the effect of the floor vibration [6]. As the result, we successfully achieved the reduction of the effect of the floor vibration with the reduction rate of over $50 \%$. However, the proper mathematical model of the system is strongly required in this method. Since the construction of the mathematical model is difficult and takes a time, it is desired that the model is not required.

In order to solve the effect of the vibration and improve the accuracy of the mass measurement, we have also manufactured a vibration exciter using an electric cylinder combining a servomotor and a ball screw. It has been confirmed that this exciter can reproduce vibration of $0.1 \mathrm{~Hz}$ to $10 \mathrm{~Hz}$. On this basis, we measured the response of the load cell when applying vibration with the manufactured exciter. In addition, we have proposed a vibration compensation method using dummy load cells [7]. 
The dummy load cell can be produced by using the 3D CAD model of the actual measuring system. The characteristics (natural frequency and damping rate) of the dummy load cell are the same as the actual system. The dummy load cell is a measuring device that can detect only vibration components contained in the weighing load cell. In this paper, we redesign the dummy load cell and aim to improve the performance of the vibration compensation method. Finally, we show the effectiveness of the proposed method through the actual experiments.

\section{SYSTEM OF VIBRATION EXPERIMENTS}

\subsection{Vibration Exciter}

The scale of the checkweigher used in this study is load cell type, the specifications of this device are as follows;

- measuring range: $12 \mathrm{~g}-3000 \mathrm{~g}$

- scale: $0.1 \mathrm{~g}$

- $\quad$ selection accuracy: $\pm 0.2 \mathrm{~g}$

A photograph of the vibration exciter is shown in Figure 1. The vibration exciter is manufactured using an electric actuator (SMC, LEY32DNZC-100) and a servomotor (Yaskawa Electric, $\Sigma$-II), it is possible to control the motor by sending a position command from the host device (PC) to the servo amplifier and to vibrate in the vertical direction. As the software for measurement and control, LabVIEW was used.

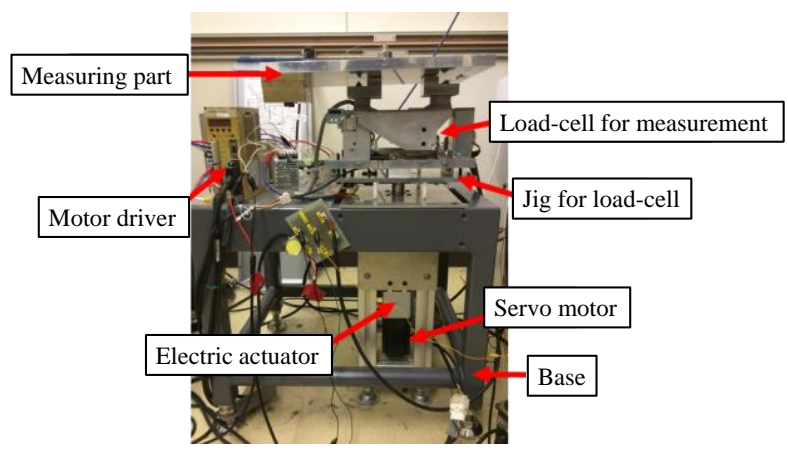

Figure 1: Photograph of vibration exciter

\subsection{Dummy Load Cell}

A dummy load cell shown in Figure 2 is installed in the checkweigher, as shown in Figure 3, for the purposes of the measurement of the floor vibration and the compensation of the vibration. The dummy load cell is required to be small because it must be placed inside the weighing conveyor. In this time, it was designed and manufactured to be less than half of the weighing load cell. The natural frequency and damping rate of the dummy load cell were adjusted using weights to coincide with those of the weighing load cell. The natural frequency and damping rate can be obtained from 3D CAD model or the mathematical model [5] of the actual measuring system.

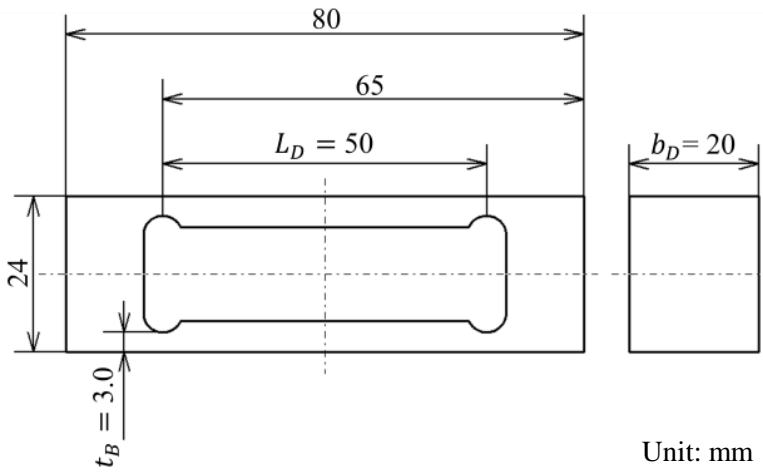

Figure 2: Specification of dummy load cell

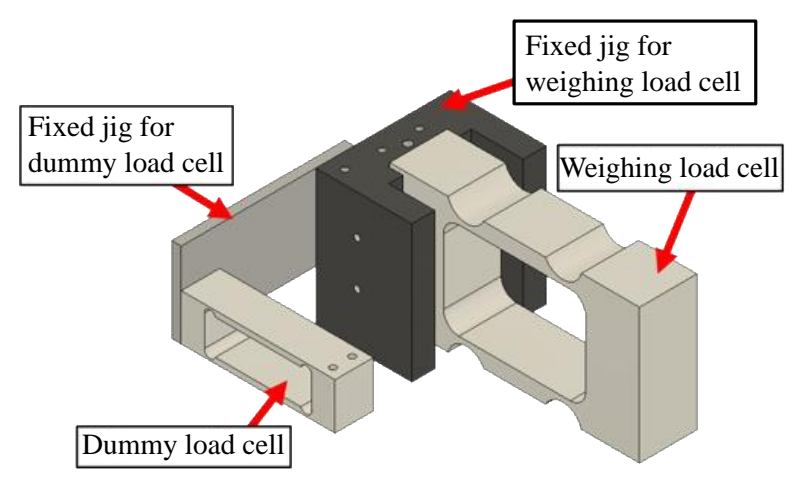

Figure 3: System of vibration compensation method

\section{PROPOSED METHOD}

To reduce the effect of the floor vibration, we proposed a compensation method using the dummy load cell. The method is to obtain the difference of the outputs between the actual load cell for mass measurement and the dummy load cell.

The block diagram of the proposed method is shown in Figure 4. In Figure 4, each element is defined as follows:

- Weighing LC: actual load cell for mass measurement

- Dummy LC B: dummy load cell (the new type)

- CKT: bridge circuit

- AMP: amplifier of signal

- LPF: low-pass filter

- $K_{I W}$ : coefficient to convert from voltage to strain

- $K_{B}$ : coefficient to convert from voltage to strain

- $\quad\left(2 b_{W} t_{W}^{2} E\right) /\left(3 L_{W}\right)$ : coefficient to convert from strain to force

- $\left(2 b_{D} t_{B}^{2} E\right) /\left(3 L_{D}\right)$ : coefficient to convert from strain to force

- $\left(m+M_{W}\right) /\left(m+M_{D}\right):$ coefficient to compensate difference between force values of both load cells

- $\frac{1}{\mathrm{~g}}$ : coefficient to convert from force to mass, $\mathrm{g}$ is the gravitational acceleration 


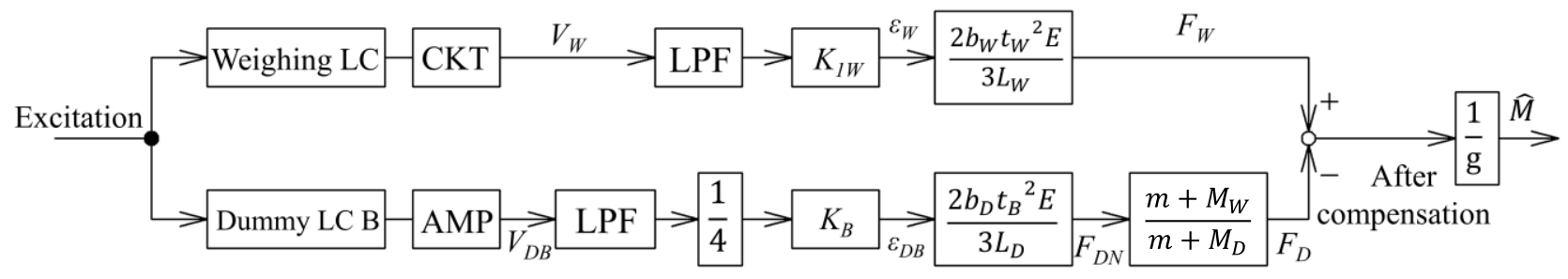

Figure 4: Block diagram of vibration compensation

Table 1: Qualitative evaluation of proposed method

\begin{tabular}{|c|c|c|c|}
\hline Frequency in Hz & Before compensation in g & After compensation in g & Reduction rate in \% \\
\hline 1 & 34.3 & 28.9 & 15.8 \\
\hline 2 & 120 & 42.6 & 64.4 \\
\hline 3 & 281 & 46.2 & 83.5 \\
\hline 5 & 646 & 55.4 & 91.4 \\
\hline
\end{tabular}

The values after the low-pass filter (LPF) in this figure calculated offline. First, the resistance change in weighing load cell is output as the voltage $V_{W}$ through the bridge circuit, and it was converted into strain according to the specification value $\left(K_{I W}=1200 \mu \mathrm{S} / \mathrm{V}\right)$. The force was calculated using the relationship between force and strain at the load cell described by equation (1).

$F=\frac{2 b t^{2} E}{3 L} \varepsilon$,

where $b$ (in $\mathrm{mm}$ ) is the length of the load cell, $t$ (in $\mathrm{mm}$ ) is the thickness of the notch, $L$ (in $\mathrm{mm}$ ) is the length between notches, and $E$ (in $\mathrm{GPa}$ ) is Young's modulus. From this relationship, the final measurement force $F_{W}$ can be obtained.

In the dummy load cell, the voltage $V_{D}$ is output by the dynamic strain amplifier (Tokyo Measuring Instruments Lab. DC-97A). At this time, since the value of 4 gauge is output directly, the value is multiplied by $1 / 4$ after the calculation of the low pass filter. The nominal force $F_{D N}$ acting on the load cell can be obtained.

Each load cell is subjected to centrifugal force due to vibration, and these forces are formulated by equations (2) and (3).

$$
\begin{aligned}
& F_{w}=\left(m+M_{W}\right) A \omega^{2} \\
& F_{D N}=\left(m+M_{D}\right) A \omega^{2} .
\end{aligned}
$$

The measured value of the dummy load cell is compensated using equation (4) so that the force caused by the vibration is equal for both load cells.

$$
F_{D}=\frac{\left(m+M_{W}\right)}{\left(m+M_{D}\right)} F_{D N},
$$

where $F_{W}$ (in $\mathrm{N}$ ) is the force applied to weighing load cell, $F_{D N}$ (in $\mathrm{N}$ ) is the force applied to dummy load cell $[\mathrm{N}], F_{D}$ (in $\mathrm{N}$ ) is the compensated force of dummy load cell, $m$ (in $\mathrm{kg}$ ) is the mass of an object to be measured, $M_{W}$ (in $\mathrm{kg}$ ) is the mass of weighing section in weighing load cell, $M_{D}$ (in $\mathrm{kg}$ ) is the mass of weighing section in dummy load cell, $A$ (in $\mathrm{mm}$ ) is the amplitude, $\omega(=2 \pi f$, in $\mathrm{rad} / \mathrm{s})$ is the angular velocity and $f$ (in $\mathrm{Hz}$ ) is the excitation frequency.

Since the proposed method is simple, it is easy to implement on the actual system. In addition, since the dynamics of the dummy load cell is considered to be the same as one of the actual load cell for measuring the mass, the difference $\widehat{M}$ may become to be 0 theoretically. Consequently, the effect of the vibration will be deleted successfully.

To achieve this, accurate dummy load cell described in section 2.2 is required. However, if experiment for estimating the natural frequency and damping rate of the system is conducted and these parameters are obtained, the mathematical model of the system is not required.

\section{EXPERIMENTAL RESULTS}

In experiments, the weight with $0.1 \mathrm{~kg}$ was put on the conveyor. The amplitude was $0.5 \mathrm{~mm}$ and the input frequency of the vibration exciter was changed from $1 \mathrm{~Hz}$ to $2 \mathrm{~Hz}, 3 \mathrm{~Hz}$ and $5 \mathrm{~Hz}$.

The qualitative evaluation and the time series responses of all the experimental results are shown in Table 1 and Figure 5, respectively. The reduction rate is calculated by

$$
\text { Reduction rate }=\frac{Y-X}{Y} \times 100[\%]
$$

where $X$ and $Y$ are the estimated mass after compensation and the estimated mass before compensation, respectively.

It can be seen from Table 1 that the effect of the vibration in the mass measurement can be reduced. In particular, the reduction rate in the vibration of $5 \mathrm{~Hz}$ is $91.4 \%$ which was the maximum reduction rate. In this calculation, we used the average value of the experimental results. 


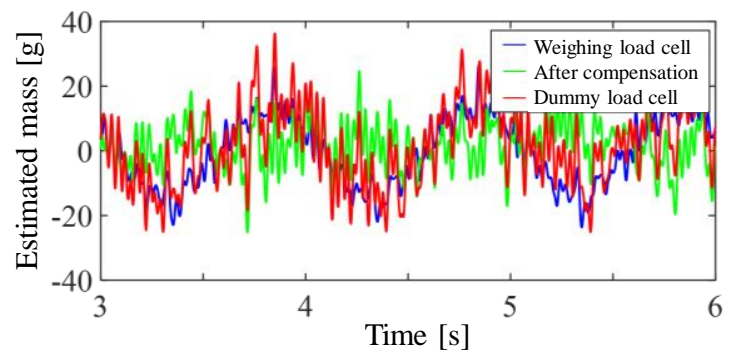

(a) $1 \mathrm{~Hz}$

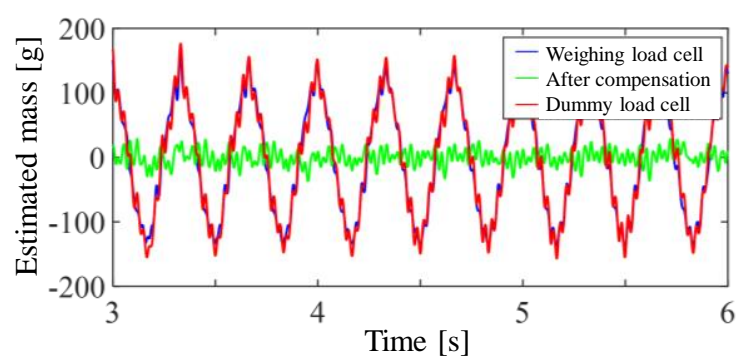

(c) $3 \mathrm{~Hz}$

Figure 5: Experimental results

It can be also seen from Figure 5 that the responses from the actual weighing load cell and the dummy load cell are almost the same. From these results, we found that the design of the dummy load cell is appropriate to duplicate the environmental vibration. We also found that the effect of the vibration can be deleted using the proposed vibration compensation method without the mathematical model of the system as in reference [7]. Consequently, the effectiveness of the proposed method is clarified from the experimental results.

The strong point of our method is that the proper mathematical model is not required to implement reduction method of the effect of the floor vibration.

\section{CONCLUSION}

To solve the effect of the vibration and improve the accuracy of the mass measurement, we manufactured the vibration exciter that can reproduce environmental vibration. Comparing the response waveforms of the weighing load cell and the dummy load cell while exciting the checkweigher attached the dummy load cell, it was confirmed that the measurement of low frequency was also possible. Moreover, it is shown that environmental vibration can be removed by the proposed compensation method using the output of dummy load cell. In the future, we plan to improve the detection sensitivity of small input signals.

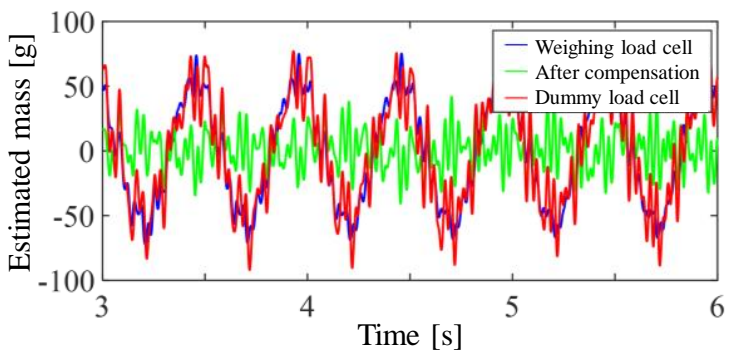

(b) $2 \mathrm{~Hz}$

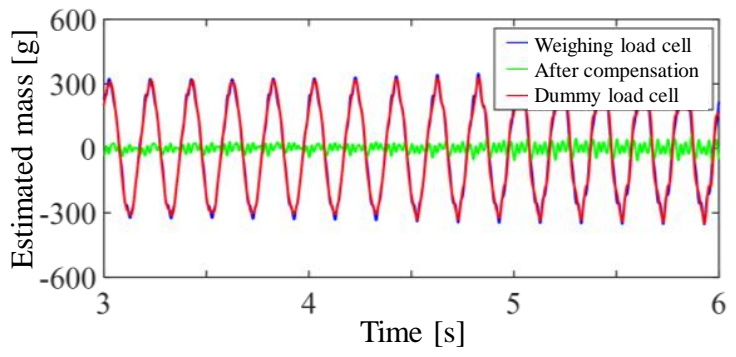

(d) $5 \mathrm{~Hz}$

\section{REFERENCES}

[1] K. Kamimura, H. Kanai, N. Chubach, "Design of optimum FIR filter for eliminating mechanical noise in weight measurement with loadcell", Acoustical Society of Japan, vol. 51 no. 11, pp. 845-853, 1995.

[2] T. Umemoto, M. Kamon, Y. Kagawa, "Improvement of Accuracy for Continuous Mass Measurement in Checkweighers with an Adaptive Notch Filter", Trans. of the Society of Instrument and Control Engineers, vol. 47 no. 10, pp. 477-484, 2011.

[3] J. Sun, Y. Fujioka, T. Ono, T. Nagao, T. Kohashi, "On the Fast and High Accurate Mass Measurement under the Conditions of Floor Vibration. On the Method of Compensating the Difference in Dynamics without On-line Identification", Japan Society for Precision Engineering, vol. 64 no. 7, pp. 1029-1034, 1998.

[4] J. Sun, Y. Fujioka, T. Ono, T. Nagao, "On the Fast and High Accurate Mass Measurement under the Conditions of Floor Vibration. On the Method of Compensating the Difference in Dynamics by Using the Approximate Polynomial Model", Japan Society for Precision Engineering, vol. 65 no. 10, pp. 1450-1455, 1999.

[5] Y. Yamakawa, T. Yamazaki, "Mathematical model of checkweigher with electromagnetic force balance system", Acta IMEKO, vol. 3, no. 2, pp. 9-13, 2014.

[6] Y. Yamakawa, T. Yamazaki, "Reduction of the effect of floor vibrations in a checkweigher using an electromagnetic force balance system", Acta IMEKO, vol. 6, no. 2, pp. 65-69, 2017.

[7] A. Tsuzura, Y. Yamakawa, T. Yamazaki, "Vibration compensation for checkweigher using dummy load cell”, Proc. of APMF, p. 80, 2019. 